\title{
Investigação das memórias escolares de estudantes universitários
}

\author{
Ingrid Luiza Neto \\ Centro Universitário do Distrito Federal - Brasília - DF - Brasil \\ Higor Barreira dos Santos \\ Centro Universitário do Distrito Federal - Brasília - DF - Brasil
}

\begin{abstract}
Resumo
Este trabalho visa investigar as memórias escolares de estudantes universitários por meio do uso de narrativas autobiográficas, buscando compreender o significado que atribuem ao espaço escolar. Embora a escola seja considerada como espaço de transmissão de conhecimentos científica e historicamente produzidos, é importante refletir que se trata de um lugar onde o sujeito se constitui, em termos sociais, físicos, emocionais e culturais. Por meio da análise de conteúdo das narrativas autobiográficas apresentadas por 105 estudantes universitários foi possível identificar 11 categorias de memórias: relacional positiva, conflituosa, lúdica, pedagógica, saudosista, hierárquica, participação familiar, alimentar, grupal transgressora, ruptura familiar e prospectiva. Os resultados indicam que os aspectos relacionais e lúdicos foram mais lembrados do que os pedagógicos. Discute-se que o levantamento de memórias escolares é uma estratégia interessante para aumentar o conhecimento acerca das práticas realizadas no espaço escolar e do significado atribuído à escola.
\end{abstract}

Palavras-chave: Lembranças; escola; narrativas biográficas.

\section{Investigating college students' school memories}

\begin{abstract}
This work aims to investigate the school memories of university students, through the use of autobiographical narratives, trying to understand the meaning they attribute to the school space. Although the school is considered as a space for the transmission of scientific and historically produced knowledge, it is important to reflect that it is a place where the subject is constituted in social, physical, emotional and cultural terms. Through the content analysis of the autobiographical narratives presented by 105 university students, it was possible to identify 11 categories of memories: positive, conflictive, playful, pedagogic, nostalgic, hierarchical, family participation, food, transgressive group, family rupture and prospective. The results indicate that relational and playful aspects were more remembered than pedagogical ones. It is argued that the collection of school memories is an interesting strategy to increase the knowledge about the practices performed in the school space and the meaning attributed to the school.
\end{abstract}

Keywords: Memories; school; biographical narratives.

\section{Investigación de las memorias escolares de estudiantes universitarios}

\section{Resumen}

En este estudio se tuvo el objetivo investigar las memorias escolares de estudiantes universitarios, por intermedio del uso de narrativas autobiográficas, buscando comprender el significado que atribuyen al espacio escolar. Aunque la escuela sea considerada como espacio de transmisión de conocimientos científicos e históricamente producidos, es importante reflexionar que se trata de un lugar en que el sujeto se constituye, en términos sociales, físicos, emocionales y culturales. Por intermedio del análisis de contenido de las narrativas autobiográficas presentadas por 105 estudiantes universitarios fue posible identificar 11 categorías de memorias: relacional positiva, conflictiva, lúdica, pedagógica, nostálgica, jerárquica, participación familiar, alimentar, grupal transgresora, ruptura familiar y prospectiva. Los resultados indican que aspectos relacionales y lúdicos fueron más recordados que los pedagógicos. Se discute que el levantamiento de memorias escolares es una estrategia interesante para aumentar el conocimiento acerca de las prácticas realizadas en el espacio escolar y del significado atribuido a la escuela.

Palabras clave: Memorias; escola; narrativas biográficas. 


\section{Introdução}

A escola é uma instituição que ocupa um espaço importante na constituição psicossocial dos indivíduos. Trata-se de um dos ambientes em que o aluno pode ter contato com uma ampla gama de conhecimentos, histórica e cientificamente sistematizados. A escola favorece, portanto, o acesso ao conhecimento a todos os cidadãos.

Entretanto, além de propiciar a apreensão do conhecimento produzido pela humanidade, cabe à escola o papel de favorecer o desenvolvimento de competências, utilizando o conhecimento apreendido no exercício efetivo da cidadania (Ministério da Educação, 2004). É um espaço em que se pode refletir sobre os comportamentos e valores presentes nas interações entre os sujeitos, sobre como o sujeito se insere na realidade à sua volta, construindo uma representação subjetiva do mundo (Ferreira, Leão, Santos, Montreozol, \& Teruya, 2009).

Assim, a instituição escolar assume diversas funções que extrapolam a dimensão pedagógica, didática e formativa. Há o papel socializador e relacional; a função lúdica; e a função transformadora, que busca a inserção dos alunos no mercado de trabalho no futuro (Aquino \& Albuquerque, 2014).

O presente trabalho visa investigar as memórias escolares de um grupo de estudantes universitários do curso de psicologia. Para tanto, foram levantadas as memórias que guardam do tempo em que frequentaram escolas de educação básica, por meio de narrativas autobiográficas, para identificar o significado que atribuem ao espaço escolar.

\section{O papel da educação e da escola}

Historicamente, a escola tem sido considerada um espaço formal de educação, que visa possibilitar o acesso aos conhecimentos produzidos e organizados cientificamente e compartilhados ao longo do tempo (Vigotsky, 1998).

No Brasil, a educação é um direito resguardado às crianças e adolescentes, tendo como principal objetivo propiciar o pleno desenvolvimento das pessoas, o preparo para o exercício da cidadania e a qualificação para o trabalho (Lei $\left.n^{\circ} 8.069,1990\right)$. Nesse contexto, a educação visa ao desenvolvimento integral do indivíduo, buscando identificar suas necessidades de desenvolvimento intelectual, físico, emocional, social e cultural.

Outra função exercida pela escola é a busca pelo controle social, por meio da seleção meritocrática e do reforço à promoção e ao progresso (Cruz \& Freitas, 2011; Jiménez \& Bernal, 2005; Silva \& Braga, 2010). Neste sentido, cabe à escola trabalhar parâmetros e valores voltados para a manutenção da ordem social e do respeito às normas. As próprias características estruturais da escola (e.g., horário, organização, conteúdos, diferenciação de papéis, prêmios, "castigos", complexidade de atividades) podem levar ao aprendizado acerca da importância de se cumprir as normas. Além disso, contribuem para que os estudantes desenvolvam atitudes de independência/dependência, rea- lização/adequação, universalismo e outras especificidades funcionais à vida em organização (Frigotto, 1984, 2015; Marinho-Araújo \& Almeida, 2010).

Há de se ressaltar, porém, que o papel social desempenhado pela escola deve extrapolar a simples preocupação com o desempenho do aluno, em termos de disciplina e/ou respeito às regras. É essencial que a escola prepare seus estudantes para a vida social, enfatizando o desenvolvimento de uma cultura de solidariedade, cidadania e respeito entre seus alunos. Esse preparo inclui também o desenvolvimento de habilidades para enfrentar situações que podem ser geradas pela violência ou levar a ela (Del Prette, 2003).

Como as práticas sociais possuem caráter cultural (Godoy \& Santos, 2014), é importante considerar que a interação entre os indivíduos e o meio cultural no qual estão inseridos influencia na constituição do psiquismo dos sujeitos. Assim, a escola é um espaço que, além de preparar os indivíduos para a vida em sociedade, propicia a apropriação dos aspectos culturais daquele grupo ou sociedade (Rego, 2003).

Considera-se, assim, que o espaço escolar não pode ser concebido como um lugar em que o professor meramente transmite conhecimentos científicos e o aluno os adquire (Freire, 1996). Trata-se de um espaço privilegiado em que as habilidades sociais de um indivíduo começam a ser desenvolvidas, seja a partir de seu convívio com os colegas de classe, ou com os professores e/ou funcionários em geral. Além disso, é também um ambiente que facilita a vivência de inúmeras e diferentes experiências afetivas (positivas ou negativas), que podem impactar significativamente no desenvolvimento de um individuo.

Em suma, a escola é um espaço de desenvolvimento e aprendizagem que deve considerar padrões relacionais, aspectos culturais, cognitivos, afetivos, sociais e históricos que estão presentes nas interações que ocorrem nesse ambiente (Dessen \& Polônia, 2007).

\section{O que pensam os estudantes sobre a escola?}

Diferentes autores enfatizam a importância de conhecer a percepção dos estudantes acerca do espaço escolar, com o intuito de investigar como os alunos atribuem significado ao contexto educacional (Aquino \& Albuquerque, 2014; Campos, 2005; Cruz, 2005; Passeggi \& cols., 2014; Passeggi, Ribeiro, Nascimento; Oliveira, \& Silva, 2015). Estudos dessa natureza compreendem que o educando deve ter direito à opinião e expressão, atuando como sujeito ativo do processo de educação.

Nesse contexto, Albuquerque, Martins, Modena e Campos (2014) consideram que a escola deve preservar o direito dos estudantes exprimirem sua opinião sobre questões que lhe digam respeito. Para os autores, a participação ativa dos alunos gera um sentimento de importância, de ser acolhido e apreciado, estimulando a reflexão crítica, a participação e a formação do vínculo social. Assim, a escola 
passa a ser um ambiente que contribui significativamente para o desenvolvimento pessoal e social do aluno.

Além disso, conhecer a percepção dos estudantes sobre o espaço escolar pode ser uma importante ferramenta para se avaliar os processos educacionais, identificando as potencialidades e os aspectos que precisam ser melhorados no contexto escolar. Spazziani (2015) levantou a percepção dos estudantes de uma escola pública, para identificar indicadores de qualidade e propor soluções para os problemas apontados pelos alunos, no que se refere ao ambiente educativo, uso de novas tecnologias e metodologias de ensino, gestão educacional, relações interpessoais e participação dos alunos no processo educativo.

Em estudo realizado com 90 crianças do Ensino Fundamental no estado da Paraíba, Aquino e Albuquerque (2014) identificaram a descrição das crianças acerca de como é a escola, os motivos pelos quais elas frequentam a escola e as atividades de que gostam e não gostam de fazer na escola. As respostas das crianças foram categorizadas em quatro dimensões gerais: a) pedagógica: conteúdos, disciplinas trabalhadas, aspectos científicos; b) relacional: relações interpessoais, amizades, conflitos; c) prospectiva: aspecto profissional e de inserção no mercado de trabalho no futuro; e d) lúdica: diversão, brincadeiras e jogos.

Passeggi e cols. (2014) analisaram as narrativas de crianças de 4 a 10 anos, em diferentes estados brasileiros, investigando o sentido que atribuem às escolas da infância. As narrativas foram analisadas por grupos de faixa etária. Crianças entre 4 e 5 anos perceberam a escola como lugar para brincar; entre 5 e 6 consideraram que é um espaço para realizar várias atividades (e.g., estudar, brincar, ler, fazer atividades); entre 6 e 8, narraram que a escola é para aprender e brincar "um pouco"; e, por fim, crianças entre 8 e 10 anos julgaram que a escola é para aprender, para ser inteligente.

Já o estudo de Becker (2006), desenvolvido em uma escola pública catarinense, demonstrou que as crianças se sentem cobradas a desempenhar mais o papel de aluno do que de crianças, já que têm pouco tempo para brincar, desenhar, cantar, conversar e movimentar-se.

Sant'Ana (2010) realizou estudo com 68 crianças de quatro escolas de Minas Gerais e observou que as crianças percebem a escola como espaço onde são privados de realizar as atividades que mais gostam. Indicou também o uso de estratégias coercitivas para reduzir a indisciplina, bem como de técnicas de ensino mais tradicionais, voltadas para cópias e exercícios suplementares.

Esses dados indicam que as crianças percebem a escola não apenas como espaço de aprender, mas também de brincar, socializar e obter melhores oportunidades no futuro. Assim, ao permitir que os estudantes relatem como visualizam as experiências que vivenciam na escola, torna-se possível identificar mais claramente as funções desempenhadas pelas instituições de ensino. Por conseguinte, torna-se possível refletir e planejar ações educativas que considerem os aspectos apontados pelos estudantes.
Outra estratégia utilizada para identificar as funções desempenhadas pela escola e a percepção que as pessoas têm do espaço escolar é o levantamento das memórias sobre o tempo em que estiveram na escola.

\section{Registrando memórias do tempo da escola}

O fato de nos lembrarmos ou nos esquecermos de certos episódios que ocorrem em nossas vidas apresenta-se como um fenômeno relativamente impreciso, uma vez que nossa memória é seletiva. Tendemos a reter e lembrar de acontecimentos que, de alguma forma ou por alguma razão, foram significativos e marcaram nossa existência num determinado momento (Lima, 2014).

Assim, nossas memórias adquirem um caráter fenomenológico, uma vez que os indivíduos consideram a experiência em si mesma, independentemente dos juízos de realidade ou de valor que espontaneamente são levados a fazer (Amatuzzi, 2009). O relevante ao se registrar memórias é considerar a visão de mundo para cada indivíduo investigado, considerando seu tempo fenomenológico e suas experiências (Moraes, 2015).

A memória pode ser individual ou coletiva (Halbwachs, 2006; Leal, 2013). A individual refere-se a lembranças das experiências vivenciadas pelo indivíduo, sem que haja a necessidade da presença de outras pessoas para confirmar (ou não) a veracidade dessa lembrança. Já a memória coletiva requer confirmações dos fatos apresentados e recordados, por meio da presença de outrem. Nesse caso, a memória individual não deixaria de existir, mas a visão com relação a ela é que se encontra enraizada em diferentes contextos, uma vez que se baseia nos pontos de vista de diferentes coparticipantes do evento em pauta.

Dessa forma, o contexto proposto aos participantes da presente pesquisa é o período escolar, sendo levantadas as suas memórias individuais e fenomenológicas em relação aos fatos vivenciados nesse período. Isso implica em dizer que não será necessário investigar a precisão dos detalhes das memórias dos indivíduos, apenas identificar os aspectos mencionados pelos participantes, partindo do pressuposto de que as lembranças eliciadas refletem os aspectos mais significativos para o indivíduo. Assim, ao solicitar que as pessoas se lembrem de fatos marcantes em sua vida escolar, provavelmente elas relatarão o que perdurou no tempo e no espaço, precisando apenas de um gatilho para se recordarem dos episódios mais significativos (Lima, 2014).

\section{Estudos sobre levantamento de memórias escolares}

Conhecer as histórias de vida e os relatos autobiográficos trazidos por diferentes pessoas sobre o tempo em que frequentaram o espaço escolar é uma técnica frequentemente utilizada por pesquisadores. Esse uso deve-se ao fato de que "o depoimento oral proporciona a composição 
de uma história mais rica e mais coerente com a realidade investigada, pois... consegue adentrar na vida dos colaboradores da investigação e na realidade pesquisada" (Antunes, 2008, p. 4165).

A técnica da narrativa autobiográfica pode focar tanto no relato de eventos passados que aconteceram à pessoa que conta a história, quanto na experiência real ou imaginada do sujeito (Andrews, Squire, \& Tamboukou, 2013). Constitui-se como uma forma de eliciar momentos históricos da vida do indivíduo, evidenciando aspectos culturais que permitem interpretar o significado atribuído pelo narrador à experiência, trazendo à tona aspectos identitários e sociais (Freitas \& Galvão, 2007). Também tem sido utilizada no campo da educação como um instrumento que possibilita a reflexão do narrador sobre sua experiência escolar, impactando inclusive na formação e na prática docente (Gaspar, Pereira, \& Passeggi, 2012; Gastal \& Avanzi, 2015; Silva \& Maia, 2010).

A ideia subjacente à narrativa autobiográfica é reordenar certas experiências vividas, refletindo sobre o discurso e sobre as emoções eliciadas pelas memórias, sob a ótica do presente (Rego, 2014). Por essa razão, vários estudos têm sido desenvolvidos com (futuros) professores, utilizando narrativas autobiográficas.

Antunes (2008) realizou um estudo com professoras alfabetizadoras e identificou que muitas escolheram tornar-se educadoras devido a lembranças positivas que tinham do tempo de escola, em especial as lembranças referentes às professoras. Esse resultado sugere que as dimensões afetiva e relacional exercem influência significativa na escoIha profissional pela carreira docente.
Esse resultado corrobora os achados de Krug, Ivo e Krug (2008) que, utilizando a abordagem fenomenológica, identificaram que professores considerados bons, i.e., que promovem a integração entre os colegas e que planejam adequadamente as atividades a serem desempenhadas, influenciam significativamente seus alunos, inclusive na escolha da profissão.

O estudo Gastal e Avanzi (2015), realizado com estudantes universitários do curso de biologia, considera que a narrativa pode estimular nos estudantes uma reflexão acerca da experiência passada, à luz de teorias aprendidas no ambiente universitário, experiência essa que passa a ser revivida e ressignificada.

Em estudo realizado junto a estudantes da graduação de cursos de licenciatura, Lima (2014) investigou as memórias do tempo de escola, utilizando a técnica da narrativa autobiográfica e da produção de um memorial. Para tanto, sugeria que os estudantes refletissem sobre diversos aspectos como: participação da família na escola, brincadeiras, festas, viagens, namoros, amizades, brigas, aprovação e reprovação, metodologia dos professores, material escolar. Os estudantes eram, assim, solicitados a buscar reflexões que exaltassem alegrias, tristezas, desafios, perdas ou conquistas. Os resultados desse estudo foram sintetizados na Tabela 1.

Essas dimensões são semelhantes às propostas por Aquino e Albuquerque (2014) e indicam que a escola elicia memórias que vão muito além de aspectos meramente pedagógicos.

Tabela 1. Dimensões do espaço escolar, conforme a percepção de estudantes de cursos de licenciatura.

\begin{tabular}{|c|c|}
\hline Dimensão & Descrição \\
\hline Perspectiva futura & $\begin{array}{l}\text { Interesse dos pais em possibilitar aos filhos melhores oportunidades de vida do que a que } \\
\text { eles próprios tiveram } \\
\text { Crença de que a escola significa uma possibilidade de mudança de vida, aprendizagem de } \\
\text { uma profissão e ascensão social }\end{array}$ \\
\hline \multirow{2}{*}{ Pedagógica } & $\begin{array}{l}\text { Percepção da escola como espaço de aprendizagem de conceitos e conhecimentos que não } \\
\text { poderiam ser ensinados/apreendidos em casa pelas famílias }\end{array}$ \\
\hline & $\begin{array}{l}\text { Necessidade de desenvolver a escrita e a leitura (no domínio lingüístico) e a prática das } \\
\text { quatro operações matemáticas (no aspecto quântico) }\end{array}$ \\
\hline Social & $\begin{array}{l}\text { Memórias saudosistas relativas a experiências vivenciadas com a família, com os amigos ou } \\
\text { aos bons professores }\end{array}$ \\
\hline Afetiva & $\begin{array}{l}\text { Ênfase em lembranças positivas, atribuindo menor relevância a situações de perdas de } \\
\text { amigos ou familiares, buscando quase sempre substituir estas lembranças ruins por outras } \\
\text { mais prazerosas }\end{array}$ \\
\hline
\end{tabular}

Fonte: Adaptado de Lima (2014). 
Resultados semelhantes foram encontrados por Moraes (2015), em estudo realizado com jovens e adultos de diferentes idades. Nesse estudo, as melhores memórias escolares relatadas não remetem à questão de aprendizagem, que, segundo o autor, deveriam ser o foco do trabalho escolar, mas sim ao processo de socialização e de atividades livres que ocorrem na escola.

Identifica-se, seja pelo relato de crianças que frequentam a escola, seja pelas lembranças das pessoas que não mais frequentam a escola, que o espaço escolar não se restringe apenas ao desenvolvimento intelectual dos alunos (dimensão pedagógica), sendo reducionista qualquer análise que desconsidere as demais funções desempenhadas pela escola, tais como a relacional / social, a afetiva, a lúdica e a prospectiva.

Grande parte das evocações diz respeito a experiências de cunho psicossocial vivenciadas pelas pessoas de maneira fenomenológica em detrimento dos aspectos cognitivos e de aprendizagem de conteúdos. Algumas escolas, contudo, demonstram uma despreocupação com a plena inserção e integração do aluno ao ambiente escolar, bem como com a prática da cidadania. Por vezes, as instituições voltam sua atenção exclusivamente para indicadores específicos de aprendizagem, treinando as crianças e adolescentes para passar em provas, vestibulares ou concursos, esquecendo-se, porém, de seu papel na formação global do indivíduo (Marinho-Araújo \& Almeida, 2010).

Assim, registrar as memórias dos indivíduos sobre o tempo de escola pode ser útil para descrever, caracterizar e analisar as histórias de vida relacionadas à educação formal e às experiências educacionais vivenciadas na escola de educação básica (Lima, 2014), contribuindo assim para a reflexão sobre o papel desempenhado pela escola e quais os impactos que ela desempenha na vida das pessoas.

\section{Método}

Para o levantamento das memórias escolares, foi utilizado o método de pesquisa do tipo narrativa, em que autobiografias e narrativas individuais são utilizadas para produzir conhecimento relacionado ao fenômeno educacional (Silva \& Maia, 2010). O estudo de narrativas considera que o ato de contar histórias desempenha um papel importante na compreensão de fenômenos sociais, em que o informante procura dar um sentido ao enredo e aos acontecimentos da vida (Jovchelovitch \& Bauer, 2010).

\section{Participantes}

Os participantes do estudo foram selecionados por conveniência. Todos os estudantes que participaram do presente estudo eram alunos da disciplina de Psicologia Escolar do curso de psicologia de um Centro Universitário localizado no Distrito Federal.
Participaram do estudo 105 estudantes, sendo a maioria do sexo feminino (81\%). A média de idade dos participantes foi de 26,83 anos $(S D=9,09)$, variando de 19 a 62 anos.

\section{Instrumento}

As memórias foram livremente evocadas por meio de estimulação verbal por parte da professora da disciplina, considerando as narrativas como um esquema autogerador (Jovchelovitch \& Bauer, 2010). Foram disponibilizadas folhas em branco e canetas aos participantes, para que pudessem registrar suas memórias do tempo de escola.

\section{Procedimentos}

Antes de iniciar o estudo, o projeto de pesquisa foi submetido e aprovado pelo Comitê de Ética em Pesquisa. Em sala de aula, os alunos foram solicitados a preencher e assinar o Termo de Consentimento Livre e Esclarecido. Em seguida, os participantes recebiam uma folha em branco e uma caneta, onde eram solicitados a escrever seu sexo e idade. Posteriormente, eram orientados a escrever de maneira livre a(s) memória(s) que tivessem do tempo em que frequentaram a escola de educação básica. Essa era a única instrução emitida aos participantes que, quando faziam algum questionamento, eram apenas orientados a escrever qualquer tipo de memória, positiva ou negativa.

Os dados foram analisados por meio da utilização da técnica de análise de conteúdo, desenvolvida por Bardin (2010). A técnica prevê a realização da análise dos principais temas apresentados nas respostas dos participantes, identificando-se as principais características associadas ao tema central, por meio de uma avaliação semântica.

Os depoimentos apresentados pelos participantes foram devidamente transcritos para o NVivo, que é um software específico para a realização de pesquisas qualitativas. Ele proporciona ao pesquisador analisar respostas a perguntas abertas, organizando os relatos feitos pelo participante por semelhanças semânticas (QSR International, 2016).

Em seguida, foram criadas categorias, em que os elementos constantes nas respostas foram classificados e agrupados conforme sua semelhança semântica.

\section{Resultados}

Como não houve limitação da quantidade de frases / episódios a serem relatados pelos participantes, grande parte deles apresentou mais de um fato que considerou relevante, totalizando 421 depoimentos, que foram considerados como unidade de análise.

Os depoimentos transcritos no NVivo foram organizados em categorias para facilitar a análise, conforme exposto na Tabela 2 
Tabela 2. Respostas dos participantes organizadas por categoria.

\begin{tabular}{|c|c|c|c|c|}
\hline \multicolumn{2}{|l|}{ Categoria } & \multirow[b]{2}{*}{$\begin{array}{l}\text { Frases significativas } \\
\text { "As melhores lembranças são as que referem às amizades, } \\
\text { à importância do bom convívio. A amizade é a melhor coisa } \\
\text { que existe". } \\
\text { "Fiz amizades com } 3 \text { colegas que uma delas é minha grande } \\
\text { amiga até hoje" } \\
\text { "Na 4ª série tive o primeiro amor de infância, coisas de } \\
\text { criança" }\end{array}$} & \multirow[t]{2}{*}{ Frequência } & \multirow[t]{2}{*}{$\mathbf{N}$} \\
\hline \multirow{2}{*}{$\begin{array}{l}\text { Dimensão relacional positiva } \\
\text { (lembranças positivas } \\
\text { relacionadas à função } \\
\text { socializadora e integradora da } \\
\text { escola) }\end{array}$} & aluno-aluno & & & \\
\hline & $\begin{array}{l}\text { aluno-professor } \\
\text { ou funcionário }\end{array}$ & $\begin{array}{l}\text { "Lembro-me de uma professora que tive que me encorajava } \\
\text { a escrever histórias que só eu e ela entendíamos, engraçado } \\
\text { como as coisas são... os professores possuem grande papel } \\
\text { nisso, desde o momento em que nos apoiam ao momento } \\
\text { que demonstram comportamentos negativos perante nós } \\
\text { alunos" }\end{array}$ & 27 & 101 \\
\hline \multicolumn{2}{|c|}{$\begin{array}{l}\text { Dimensão lúdica (lembranças relacionadas à } \\
\text { função de diversão exercida pelas escolas por } \\
\text { meio de brincadeiras, esportes e jogos) }\end{array}$} & $\begin{array}{l}\text { "Lembro especialmente das atividades recreativas, sair para o } \\
\text { zoológico, festas juninas e etc" } \\
\text { "No ensino médio, a professora de educação física deixava } 1 \\
\text { vez por mês brincarmos de guerra de balão d'agua; era muito } \\
\text { divertido, no final saíamos todos molhados" }\end{array}$ & 89 & 89 \\
\hline \multirow[t]{2}{*}{$\begin{array}{l}\text { Dimensão relacional } \\
\text { conflituosa (lembranças } \\
\text { negativas relacionadas } \\
\text { à função socializadora } \\
\text { e integradora da escola, } \\
\text { exclusão social, bullying) }\end{array}$} & aluno-aluno & $\begin{array}{l}\text { "Uma menina bem mais velha que eu me chamou para brigar" } \\
\text { "Os alunos da turma dava risadas de mim, me ameaçavam, } \\
\text { não queriam fazer trabalho comigo. Uma vez, chegou ao } \\
\text { extremo de roubarem as folhas do meu fichário" } \\
\text { "No Ensino médio pessoas também me perturbavam por eu } \\
\text { usar muito roupas pretas, já fui até ameaçado por eles. Isso } \\
\text { me causou bastante sofrimento na época" }\end{array}$ & 52 & \multirow[b]{2}{*}{71} \\
\hline & $\begin{array}{l}\text { aluno-professor } \\
\text { ou funcionário }\end{array}$ & $\begin{array}{l}\text { "Fui humilhada por uma professora dentro da sala de aula" } \\
\text { "Eu tinha poucos amigos porque era gorda e sofria } \\
\text { preconceito do professor de educação física" }\end{array}$ & 19 & \\
\hline \multicolumn{2}{|c|}{$\begin{array}{l}\text { Dimensão pedagógica (lembranças relacionadas à } \\
\text { função didática e formativa da escola, conteúdos, } \\
\text { projetos, notas, dificuldades de aprendizagem, } \\
\text { tarefas de casa, provas, etc) }\end{array}$} & $\begin{array}{l}\text { "Lembro das aulas de matemática que eu gostava e das } \\
\text { tabuadas que tínhamos que decorar" } \\
\text { "Me lembro da felicidade que eu ficava quando aprendia } \\
\text { alguma matéria de matemática" }\end{array}$ & 58 & 58 \\
\hline \multicolumn{2}{|c|}{$\begin{array}{l}\text { Dimensão saudosista (lembranças saudosistas e } \\
\text { nostálgicas do tempo de escola, considerando-o } \\
\text { como o "melhor tempo de todos") }\end{array}$} & $\begin{array}{l}\text { "Tenho boas lembranças e histórias do período escolar que } \\
\text { ficarão marcadas eternamente" } \\
\text { "As minhas lembranças do tempo de escola têm um gostinho } \\
\text { de saudade, uma nostalgia maravilhosa e me sinto bem em } \\
\text { voltar nela" }\end{array}$ & 26 & 26 \\
\hline
\end{tabular}

Os dados da Tabela 2 indicam que a maior parte das memórias dos participantes faz menção à dimensão Relacional Positiva, em que são enfatizadas as relações estabelecidas com alunos e professores, de maneira saudável e adequada.

Em seguida, foi apontada a dimensão Lúdica, em que se encontram as brincadeiras, gincanas, festas, bem como as atividades desportivas realizadas pelos participantes no tempo que frequentaram a escola.

A dimensão Lúdica também foi expressa nas memórias referentes a professores que ministravam aulas divertidas e dinâmicas.
A dimensão de Relações Conflituosas foi bastante presente nas lembranças dos participantes, sendo a terceira categoria mais frequente. Esse resultado sugere que a escola ainda é um espaço em que práticas excludentes são muito frequentes, em maior escala praticadas pelos colegas $(n=52)$ e em menor escala pelos professores ou funcionários da escola $(n=19)$.

A dimensão Pedagógica, apesar de importante, apareceu como quarta mais frequente, indicando que as questões referentes ao conteúdo, notas, provas, tarefas de casa ficaram na memória dos participantes. 
Tabela 2. (continuação).

\begin{tabular}{|c|c|c|c|}
\hline Categoria & Frases significativas & Frequência & $\mathbf{N}$ \\
\hline $\begin{array}{l}\text { Dimensão hierárquica (lembranças relacionadas } \\
\text { à função reguladora para seguimento de padrões } \\
\text { hierárquicos, de disciplinas e de regras na } \\
\text { sociedade) }\end{array}$ & $\begin{array}{l}\text { "Na primeira série minha professora duvidou que eu havia feito } \\
\text { a tarefinha no caderno de caligrafia por que a minha letra estava } \\
\text { idêntica à dela, gritou comigo na frente da turma e pediu para } \\
\text { que eu fizesse novamente. Voltei para minha cadeira chorando } \\
\text { e só depois que eu refiz ela ficou convencida e se arrependeu } \\
\text { das coisas que havia me dito" } \\
\text { "Lembro de não poder comer, beber ou mascar chiclete" } \\
\text { "Queria usar esmalte escuro e piercing e a escola não permitia" }\end{array}$ & 18 & 18 \\
\hline $\begin{array}{l}\text { Dimensão participação familiar (lembranças } \\
\text { sobre a importância e presença da família no } \\
\text { tempo em que frequentava a escola) }\end{array}$ & $\begin{array}{l}\text { "Meu pai me estimulava a estudar } 1 \text { a } 2 \text { horas por dia" } \\
\text { "Lembro do meu avô me levando de bicicleta para a escola" }\end{array}$ & 9 & 9 \\
\hline $\begin{array}{l}\text { Dimensão alimentar (lembranças referentes à } \\
\text { alimentação obtida na escola) }\end{array}$ & $\begin{array}{l}\text { "Lembro de comprar lanche na vendinha" } \\
\text { "Na hora do lanche, o macarrão era servido dentro dos copos" }\end{array}$ & 6 & 6 \\
\hline $\begin{array}{l}\text { Dimensão grupal transgressora (lembranças } \\
\text { relativas ao apoio ou pressão social vivenciados } \\
\text { na escola, para realizar transgressões ) }\end{array}$ & $\begin{array}{l}\text { "Muitas decisões eram tomadas em favor do grupo inteiro. } \\
\text { Lembro que erámos um grupo com mais de } 5 \text { pessoas e quando } \\
\text { alguém brigava com uma, todas tinham que ficar com raiva" } \\
\text { "Fui ameaçada de levar uma surra de } 10 \text { garotas que não } \\
\text { gostavam de mim e meus amigos da escola me escoltaram } \\
\text { na saída da aula" }\end{array}$ & 6 & 6 \\
\hline $\begin{array}{l}\text { Dimensão ruptura familiar (lembranças que remetem } \\
\text { à necessidade de deixar a família para ir à escola) }\end{array}$ & $\begin{array}{l}\text { "Lembro do primeiro dia de aula e do sentimentos divididos } \\
\text { entre deixar minha mãe e ganhar um mundo" } \\
\text { "sentia o coração apertado por saber que teria que deixar } \\
\text { minha mãe em casa, para ir à escola" }\end{array}$ & 4 & 4 \\
\hline \multirow[t]{2}{*}{$\begin{array}{l}\text { Dimensão prospectiva (lembranças sobre a } \\
\text { função transformadora da escola, no aspecto } \\
\text { profissional e de inserção no mercado de } \\
\text { trabalho no futuro) }\end{array}$} & $\begin{array}{l}\text { "No ensino médio, me dei conta que, para o melhor do meu } \\
\text { futuro, eu deveria me esforçar }\end{array}$ & 4 & 4 \\
\hline & TOTAL & $392^{*}$ & \\
\hline
\end{tabular}

* os demais depoimentos, apresentados em menor escala, não se enquadraram nas categorias definidas na

Tabela 2

Em seguida, foi indicada pelos participantes a existência de memórias Saudosistas, revelando que o tempo de escola marca muito a vida dos indivíduos, sendo, por vezes, considerada como "a melhor fase da vida". A dimensão Hierárquica também foi retratada pelos participantes, ressaltando a função disciplinadora da escola.

A importância da família foi apresentada de duas formas: a) dimensão Participação Familiar ( $n=9)$, em que os participantes revelaram a importância da presença da família no processo escolar, auxiliando no desempenho das tarefas e; b) Ruptura Familiar ( $n=4)$, em que foi explicitada a dificuldade dos participantes em deixar a família para ir para a escola.

Em menor escala, foram citadas memórias que remetem às dimensões Grupal Transgressora (formação de grupos na escola para realizar pequenas transgressões, como "matar aula", por exemplo) e Prospectiva (possibilidade de crescimento por meio dos estudos).

Também foram identificadas outras 29 lembranças que não se encaixaram nas categorias apresentadas na Tabela 2 (e.g., "gravidez na adolescência", "o vento frio que batia na sala de aula", "torcer para chegar logo as férias", dentre outras).

\section{Discussão}

A escola é um lugar que proporciona diversas memórias (consideradas boas ou ruins) e possui importância ímpar na formação dos indivíduos. Como descrito por Rolla (2005), nem sempre as memórias escolares são relacionadas aos conteúdos científicos aprendidos, mas a outros aspectos, 
como as paixões platônicas, a notícia da morte da mãe em meio à aula ou as correspondências em anonimato.

Nesse sentido, percebe-se que muitas vezes os profissionais da educação supervalorizam a dimensão $P e-$ dagógica, entendendo que esta permanecerá na memória das pessoas, resistindo à ação do tempo e colaborando para formação dos alunos como cidadãos. Em contraposição, o que se observou nesse estudo é que a dimensão Pedagógica, apesar de ser supervalorizada pelos educadores, foi a quarta memória mais recorrente entre os relatos, sendo a dimensão Relacional Positiva a mais frequente.

Interessante observar que os relatos sugerem que as relações positivas ocorrem de maneira natural no ambiente escolar, não havendo necessariamente um estímulo por parte da escola. Assim, os resultados do presente estudo corroboram a indicação de Becker (2006) de que nos espaços escolares quase não há locais reservados ou propícios para que as relações entre os alunos se estabeleçam. Portanto, cabe à escola incorporar essas variáveis relacionais em sua prática, promovendo atividades mais dinâmicas e integradoras.

Assim, essa dimensão social assumida pela escola extrapola a simples preocupação com o desempenho social em termos de disciplina e controle em sala de aula e abrange a preparação para a vida social, considerando:

a) o papel da competência social dos alunos como correlato ou fator de aprendizagens acadêmicas; b) a viabilidade e a necessidade de incluir as habilidades sociais como objetivo de uma educação (regular e especial) comprometida com a formação para a cidadania e para a vida social em geral e; c) a análise das condições de ensino em suas relações com o repertório de habilidades sociais profissionais do professor (Del Prette, 2003).

No que tange à dimensão Lúdica, ressalta-se a importância do professor para a formação, não apenas intelectual, mas social e afetiva do indivíduo. Professores que ministravam aulas dinâmicas e participativas foram lembrados e descritos positivamente pelos participantes, corroborando os achados de Krug e cols. (2008). Este fato chama a atenção para o desenvolvimento de atividades de formação do professor, com o intuito de apresentar novas ferramentas técnico-didáticas que podem ser utilizadas em sala de aula, a fim de promover um maior envolvimento por parte dos alunos. Além disso, também cabe ressaltar a importância de se resgatar o vínculo afetivo entre professor e aluno, para que o processo de ensino-aprendizagem ocorra de maneira suave e natural, para ambas as partes.

A escola também funciona como ferramenta para o controle social e respeito aos níveis hierárquicos (Cruz \& Freitas, 2011; Jiménez \& Bernal, 2005; Silva \& Braga, 2010). No presente estudo, os relatos colhidos ilustraram essa dinâmica das normas sociais, onde o aluno não deve questionar ou ultrapassar os limites daquele com poder maior (que no contexto escolar geralmente é o professor). Como consequência, a escola pode contribuir para a formação de cidadãos que apenas realizam, de maneira operacional, as atividades ordenadas, sem fazer questionamentos e sem repertório comportamental necessário para apresentar novas propostas e ideias.

Chamou a atenção o quantitativo de participantes que se sentiram excluídos no período escolar, demostrando em seus relatos várias recordações relacionadas à "falta de amizade" ou "sentimento de solidão", revelando dificuldade para estabelecer contatos sociais. Esses participantes não citaram como eram suas notas ou o que realizavam de bom em sua escola, atribuindo maior significado à questão da sua dificuldade de inserção no contexto social. Por outro lado, alunos que relataram ser mais sociáveis demonstraram possuir boas recordações da escola. Esse resultado, mais uma vez, reforça que a escola é um espaço de convivência social, e que os profissionais da educação devem estar atentos à maneira como as relações interpessoais se estabelecem no ambiente escolar. É importante cuidar das relações que ocorrem na comunidade escolar, potencializando as interações positivas e minimizando conflitos.

Foi possível identificar as frustações vividas pelos participantes durante o período escolar, que podem perdurar durante anos, acarretando em uma série de sofrimentos. É interessante notar que a falta de vínculos e o julgamento dos demais colegas podem fazer com que o indivíduo se culpe e acabe ele mesmo se excluindo do grupo social. Vivências como essa podem ser utilizadas pelos professores para trabalhar as questões relacionadas ao preconceito e segregação, enfatizando a importância do respeito às diferenças, contribuindo assim para a construção da cidadania e de uma cultura de respeito às diferenças. Em um dos relatos, observou-se que o professor reforçou as "piadas" e chacotas realizadas com um aluno pelos colegas da sala, o que pode ter impactado negativamente na construção da autoimagem desse aluno.

A participação da família como agente auxiliador no direcionamento escolar apareceu nos relatos, revelando o esforço dos pais para que seus filhos possam ter um futuro melhor do que o seu. A escola passa a representar para os pais uma possibilidade de ascensão social para seus filhos, tornando-os mais exigentes, chegando a exercer certa pressão para que sejam bem sucedidos (Fevorini \& Lomônaco, 2009). Essa pressão social pode ultrapassar certos limites, levando a criança ou o adolescente a se cobrar cada vez mais, não se permitindo errar, podendo levar a um adoecimento psíquico.

Além disso, também foi observada a dificuldade de alguns participantes em deixar a família, onde o ato de ir para a escola representava uma certa ruptura familiar. Sabe-se que, depois da família, a escola geralmente é o segundo grupo social no qual o sujeito se insere. É possível evidenciar através dos relatos que essa ruptura pode trazer ao individuo certa angústia e/ou ansiedade ao saber que terá que deixar os cuidados de seus pais e adentrar em um novo ambiente, ficando aos cuidados de outras pessoas. Cabe à escola trabalhar essa resistência, fazendo com que esse su- 
jeito ganhe confiança em si mesmo para adentrar esse novo contexto e reforce a autonomia dos seus atos, fortalecendo assim, seu comportamento perante novas situações.

Por fim, pode-se dizer que de maneira geral os resultados aqui obtidos corroboraram os diversos estudos já realizados sobre o assunto, especialmente no que tange às diversas funções adotadas pela escola, além da pedagógica. No contexto escolar inicia-se um universo de possibilidades para a formação psicossocial do individuo e é necessário o esforço dos profissionais que atuam nesse contexto para a formação de cidadãos que venham a contribuir de forma positiva com a sociedade. Porém, devemos repensar as diversas estratégias, para que esses indivíduos não apenas reproduzam padrões já estabelecidos, mas questionem as maneiras impostas de se fazer o mundo e atuem em uma sociedade que, muitas vezes, delimita as possibilidades.

Pesquisas como a que foi relatada no presente estudo podem contribuir para a compreensão dos aspectos que permeiam a vida escolar, refletindo sobre o impacto que as vivências escolares têm na formação do indivíduo. Levantar as memórias do tempo de escola por meio de narrativas autobiográficas é uma estratégia frutífera para se compreender o significado atribuído ao espaço escolar, podendo indicar o quanto nossas experiências nos constroem como sujeitos. Além disso, as narrativas apresentadas podem incitar o desenvolvimento de novas práticas educativas, que considerem a formação integral dos indivíduos, nos aspectos relacionais, culturais, cognitivos, afetivos, sociais e históricos. Assim, espera-se que estudos futuros possam ser desenvolvidos nessa temática para que possamos cada vez mais construir uma escola capaz de deixar apenas boas recordações em todos os que dela participam.

\section{Referências}

Albuquerque, O.M.R., Martins, A.M., Modena, C.M., \& Campos, H.M. (2014). Percepção de estudantes de escolas públicas sobre o ambiente e a alimentação disponível na escola: Uma abordagem emancipatória. Saúde Sociedade, 23(2), 604-615. Recuperado: 14 jul. 2016. Disponível: http://www.scielo.br/pdf/sausoc/v23n2/01041290-sausoc-23-2-0604.pdf

Amatuzzi, M.M. (2009). Psicologia fenomenológica: Uma aproximação teórica humanista. Estudos de Psicologia, 26(1), 93100. Recuperado: 16 jul. 2016. Disponível: http://www.scielo.br/ pdf/estpsi/v26n1/a10v26n1.pdf

Andrews, M., Squire, C., \& Tamboukou, M. (2013). Doing narrative research. Los Angeles: Sage.

Antunes, H.S. (2008). Lembranças escolares de professoras alfabetizadoras: Possibilidades de reflexão na formação de professores. Anais do VIII Congresso Nacional de Educação EDUCERE (pp. 4163-4176). PUC-PR, Santa Maria. Recuperado: 10 jun. 2016. Disponível: http://www.pucpr.br/eventos/educere/ educere2008/anais/pdf/599_670.pdf
Aquino, F.S.B. \& Albuquerque, J.A. (2014). O que pensam as crianças sobre a escola? Uma análise de relatos e desenhos infantis. Em R.S.L. Guzzo (Org), Psicologia escolar: Desafios e bastidores na educação pública (pp. 55-83). Campinas: Alínea.

Bardin, L. (2010). Análise de conteúdo. Portugal: Edições 70.

Becker, R. (2006). A constituição da infância: O que dizem as crianças de uma escola pública catarinense sobre a experiência de ser criança e de ser aluno. Dissertação de mestrado, Universidade do Estado de Santa Catarina, Florianópolis, SC.

Campos. M.M. (2005). Porque é importante ouvir a criança? A participação das crianças pequenas na pesquisa científica. Em S.H.V. Cruz (Org), A criança fala: a escuta de crianças em pesquisas (pp. 35-42). São Paulo: Cortez.

Cruz, S.H.V. (2005). Ouvir crianças: Uma tarefa complexa e necessária. Em M.P.R. Souza (Org), Ouvindo crianças na escola: Abordagens qualitativas e desafios metodológicos para a psicologia (pp 11-21). São Paulo: Casa do Psicólogo.

Cruz, P.A.S. \& Freitas, S.A. (2011). Disciplina, controle social e educação escolar: Um breve estudo à luz do pensamento de Michel Foucault. Revista do Laboratório de Estudos da Violência da UNESP/Marília, 7, 36-49.

Del Prette, Z.A.P. (2003). Psicologia escolar e educacional, saúde e qualidade de vida: Explorando fronteiras. Campinas: Alínea.

Dessen, M.A. \& Polônia, A.C. (2007). A família e a escola como contextos de desenvolvimento humano. Paidéia, 17(36), 21-32.

Ferreira, L.C., Leão, I.B., Santos, L.G., Montreozol, J.R., \& Teruya, P.S. (2009). Educação escolar: Uma possibilidade real de combate ao preconceito de identidade de gênero. Anais do XV Encontro Nacional da Associação Brasileira de Psicologia Social ABRAPSO. Faculdade Integrada Tiradentes - FITs, Maceió. Recuperado: 23 jun. 2016. Disponível: http://www.abrapso.org.br/siteprincipal/index. php?option=com_content\&task=view\&id=342\&ltemid=96

Fevorini, L.B. \& Lomônaco, J.F. (2009). O envolvimento da família na educação escolar dos filhos: Um estudo exploratório com pais das camadas médias. Psicologia da Educação, 28, 73-89.

Freitas, D. \& Galvão, C. (2007). O uso de narrativas autobiográficas no desenvolvimento profissional de professores. Ciências \& Cognição, 12, 219-233.

Freire, P. (1996). Pedagogia da autonomia: Saberes necessários à prática educativa. São Paulo: Paz e Terra.

Frigotto, G. (1984). A produtividade da escola improdutiva. (8 ${ }^{\mathrm{a}}$ ed). São Paulo: Cortez.

Frigotto, G. (2015). A produtividade da escola improdutiva 30 anos depois: Regressão social e hegemonia às avessas. Trabalho 
Necessário, 13(20), 206-233.

Gaspar, M.M.G., Pereira, F., \& Passeggi, M.C. (2012). As narrativas autobiográficas e a formação de professores: Uma reflexão sobre o diário de acompanhamento. Anais do $V$ Congresso Internacional de Pesquisas Autobiográficas. Porto Alegre: Rio Grande do Sul. Recuperado: 06 jan. 2017. Disponível: http://www. fpce.up.pt/iiijornadashistoriasvida/pdf/3_As\%20narrativas $\% 20$ autobiograficas $\% 20$ e $\% 20 a \% 20$ formacao\%20de\%20professores.pdf

Gastal, M.L. \& Avanzi, M.R. (2015). Saber da experiência e narrativas autobiográficas na formação inicial de professores de biologia. Ciência e Educação, 21(1), 149-158.

Godoy, E.V. \& Santos, V.M. (2014). Um olhar sobre a cultura. Educação em Revista, 30(3), 15-41. Recuperado: 08 jan. 2017. Disponível: http://www.scielo.br/scielo.php?script=sci_arttext\&pid=S0102$46982014000300002 \&$ Ing=en\&nrm=iso

Halbawchs, M. (2006). A memória coletiva. São Paulo: Centauro.

Jiménez, M.V.M., Bernal, A.O. (2005). Funciones (re)veladas de la educación contemporânea: Aproximación crítica desde la psicologia social de la educación en españa. Revista Iberoamericana de Educación, 37, 175-203.

Jovchelovitch, S. \& Bauer, M.W. (2010). Entrevista narrativa. Em M.W. Bauer \& G. Gaskell (Orgs.), Pesquisa qualitativa com texto, imagem e som: Um manual prático (pp. 90-113). Petrópolis: Vozes.

Krug, R.R., Ivo, A.A., \& Krug, H.N. (2008). As lembranças significativas do tempo da educação física escolar na educação básica pelos licenciandos do CEFD/UFSM: colaborando com o "aprender a ser professor". Anais do Simpósio Nacional de Educação Física. ESEF/UFPel, Pelotas. Recuperado: 15 nov. 2016. Disponível: http://boletimef.org/biblioteca/2174/As-lembrancas-significativasdo-tempo-da-Educacao-Fisica-escolar

Leal, L.A.M. (2013). Memória, rememoração e lembrança em Maurice Halbwachs. Linguagem, 18, 45-52. Recuperado: 14 jun. 2016. Disponível: http://www.letras.ufscar.br/linguasagem/edicao18/ artigos/045.pdf

Lei $n^{\circ} 8.069$, de 13 de julho de 1990 (1990, 13 de julho). Dispõe sobre o Estatuto da Criança e do Adolescente e dá outras providências. Brasília: Presidência da República. Recuperado: 10 set. 2016. Disponível: http://www.planalto.gov.br/ccivil_03/leis/L8069.htm

Lima, J.G. (2014). Lembranças do meu tempo de escola: História e memória de vida educacional de graduandos em cursos de licenciatura através de memorial. Anais do XII Encontro Nacional da História Oral: Política, ética e conhecimento. Universidade Federal do Piauí, Teresina. Recuperado: 14 jun. 2016. Disponível: http://www.encontro2014.historiaoral.org.br/resources/ anais/8/1397001287_ARQUIVO_LembrancasdoMeuTempodeEscola_ HistoriaeMemoriadeVidaEducacionaldeGraduandoemCursosdeLicenciatura AtravesdeMemorial.pdf
Marinho-Araújo, C.M. \& Almeida, S.F.C. (2010). Psicologia escolar: Construção e consolidação da identidade profissional. Campinas: Alínea.

Ministério da Educação (2004). Educação inclusiva. Brasília: Secretaria de Educação Especial. Recuperado: 05 jan. 2017. Disponível: http://portal.mec.gov.br/seesp/arquivos/pdf/aescola.pdf

Moraes, S.C. (2015). Escola, histórias e memórias: O que dizem jovens e adultos. Anais do I Congresso Internacional de Pesquisa (Auto)biográfica. Biograph, Porto Alegre. Recuperado: 05 mai. 2016. Disponível: http://websmed.portoalegre.rs.gov.br/escolas/ revistavirtualagora/artigos/salete.pdf

Passeggi, M.C., Furlanetto, E.C., De Conti, L., Chaves, I.E.M.B., Gomes Gilvete, M. O., Gabriel, L., \& Roch, S.M. (2014). Narrativas de crianças sobre as escolas da infância: Cenários e desafios da pesquisa (auto)biográfica. Educação, 39(1), 85-104.

Passeggi, M.C., Ribeiro, F.F.M., Nascimento, G.L.S., Oliveira, R.C.A.M., \& Silva, V.C.O. (2015). O uso de narrativas autobiográficas na pesquisa qualitativa em educação. Anais do Congresso Ibero Americano em Investigação Qualitativa em Educação (pp. 248-253). Universidade Tiradentes, Aracaju, Brasil. Recuperado: 08 jan. 2017. Disponível: http://proceedings.ciaiq. org/index.php/ciaiq2015/article/view/253

QSR International. (2016). Visão geral do NVivo. Recuperado: 16 mar. 2016. Disponível: http://download.qsinternational.com/Resource/ NVivo10/NVivo-10-Overview-Portuguese.pdf

Rego, T.C. (2003). Memórias de escola: Cultura escolar e constituição de singularidades. Petrópolis: Vozes.

Rego, T.C. (2014). Trajetória intelectual de pesquisadores da educação: A fecundidade do estudo dos memoriais acadêmicos. Revista Brasileira de Educação, 19(58), 779-800.

Rolla, L.C.S. (2005). Histórias dos tempos de escola: Memórias e aprendizado. História da Educação, 17, 185-186.

Sant'Ana, R.B. (2010). Criança-sujeito: Experiências de pesquisa com alunos de escolas públicas. Em M.P.R. Souza (Org.), Ouvindo crianças na escola: Abordagens qualitativas e desafios metodológicos para a psicologia (pp. 23-50). São Paulo: Casa do Psicólogo.

Silva, M.A. \& Braga, M.V.A. (2010). Controle social em educação básica pública. Jornal de Políticas Educacionais, 81(8), 91-97.

Silva, F.C.R. \& Maia, S.F. (2010). Narrativas autobiográficas: Interfaces com a pesquisa sobre formação de professores. Anais do VI Encontro de Pesquisa em Educação da UFPI. Teresina: Piauí. Recuperado: 08 jan. 2017. Disponível: http://leg. ufpi.br/subsiteFiles/ppged/arquivos/files/VI.encontro.2010/GT.1/ GT_01_22.pdf 
Spazziani, M.D. (2015). Indicadores de qualidade da educação: Estudo sobre a percepção de alunos do ensino fundamental sobre o ambiente educativo de uma escola pública. Anais da $37^{a}$ Reunião Nacional da ANPED. ANPED, Florianópolis. Recuperado: 14 jul. 2016. Disponível: http://www.anped.org.br/sites/default/ files/trabalho-gt13-4421.pdf
Vigotsky, L.S. (1998). A formação social da mente: O desenvolvimento dos processos psicológicos superiores. São Paulo: Martins Fontes.

Recebido em: 04 de setembro de 2016 Aprovado em: 18 de janeiro de 2017

\section{Sobre os autores}

Ingrid Neto (ingridluizaneto@gmail.com)

Doutora em Psicologia. Centro Universitário do Distrito Federal - Brasília-DF.

Higor Barreira (higor3373@hotmail.com)

Graduado em Psicologia. Centro Universitário do Distrito Federal - Brasília-DF. 